\title{
Early differences in islets from prediabetic NOD mice: combined microarray and proteomic analysis
}

\author{
Inne Crèvecoeur ${ }^{1}$ - Valborg Gudmundsdottir ${ }^{2}$ - Saurabh Vig ${ }^{1}$. \\ Fernanda Marques Câmara Sodré ${ }^{1}$ - Wannes D'Hertog ${ }^{1}$ • Ana Carolina Fierro ${ }^{3}$. \\ Leentje Van Lommel ${ }^{4}$. Conny Gysemans ${ }^{1} \cdot{\text { Kathleen } \text { Marchal }^{3} \text { • Etienne Waelkens }}^{5,6}$. \\ Frans Schuit $^{4} \cdot$ Søren Brunak ${ }^{2,7} \cdot$ Lut Overbergh $^{1} \cdot$ Chantal Mathieu $^{1}$
}

Received: 8 July 2016 / Accepted: 25 November 2016/Published online: 12 January 2017

(C) Springer-Verlag Berlin Heidelberg 2017

\begin{abstract}
Aims/hypothesis Type 1 diabetes is an endocrine disease where a long preclinical phase, characterised by immune cell infiltration in the islets of Langerhans, precedes elevated blood glucose levels and disease onset. Although several studies have investigated the role of the immune system in this process of insulitis, the importance of the beta cells themselves in the initiation of type 1 diabetes is less well understood. The aim of this study was to investigate intrinsic differences present in the islets from diabetes-prone NOD mice before the onset of insulitis.

Methods The islet transcriptome and proteome of 2-3-week-old mice was investigated by microarray and 2-dimensional
\end{abstract}

Lut Overbergh and Chantal Mathieu contributed equally to this work.

Electronic supplementary material The online version of this article (doi:10.1007/s00125-016-4191-1) contains peer-reviewed but unedited supplementary material, which is available to authorised users.

Lut Overbergh

lutgart.overbergh@kuleuven.be

1 Laboratory for Clinical and Experimental Endocrinology, KU Leuven, Herestraat 49 bus 902, 3000 Leuven, Belgium

2 Department of Bio and Health Informatics, Technical University of Denmark, Lyngby, Denmark

3 Department of Information Technology, IMinds, Faculty of Sciences, Ghent University, Ghent, Belgium

4 Gene Expression Unit, Department of Cellular and Molecular Medicine, KU Leuven, Leuven, Belgium

5 SyBioMa, KU Leuven, Leuven, Belgium

6 Laboratory of Protein Phosphorylation and Proteomics, KU Leuven, Leuven, Belgium

7 The Novo Nordisk Foundation Center for Protein Research, University of Copenhagen, Copenhagen, Denmark difference gel electrophoresis (2D-DIGE), respectively. Subsequent analyses using sophisticated pathway analysis and ranking of differentially expressed genes and proteins based on their relevance in type 1 diabetes were performed.

Results In the preinsulitic period, alterations in general pathways related to metabolism and cell communication were already present. Additionally, our analyses pointed to an important role for post-translational modifications (PTMs), especially citrullination by PAD2 and protein misfolding due to low expression levels of protein disulphide isomerases (PDIA3, 4 and 6), as causative mechanisms that induce beta cell stress and potential auto-antigen generation. Conclusions/interpretation We conclude that the pancreatic islets, irrespective of immune differences, may contribute to the initiation of the autoimmune process.

Data availability All microarray data are available in the ArrayExpress database (www.ebi.ac.uk/arrayexpress) under accession number E-MTAB-5264.

Keywords 2D-DIGE $\cdot$ Beta cells $\cdot$ Intrinsic differences · Microarray $\cdot$ NOD mice $\cdot$ Pathway analysis $\cdot$ Post-translational modifications $\cdot$ Type 1 diabetes

$\begin{array}{ll}\text { Abbreviations } \\ \text { 2D-DIGE } & \text { 2-Dimensional difference gel electrophoresis } \\ \text { ER } & \text { Endoplasmic reticulum } \\ \text { FDR } & \text { False discovery rate } \\ \text { GO } & \text { Gene ontology } \\ \text { IPA } & \text { Ingenuity pathway analysis } \\ \text { NOR } & \text { Non-obese resistant } \\ \text { PPI } & \text { Protein-protein interaction } \\ \text { PTM } & \text { Post-translational modification }\end{array}$




\section{Introduction}

The NOD mouse, which spontaneously develops diabetes, is an important model of type 1 diabetes. Since its development, more than 30 years ago, this strain has provided a wealth of information on the development of this complex autoimmune disease [1]. In the prediabetic phase, islets become infiltrated by macrophages and dendritic cells, followed by CD4+ and CD8+ T cells. This process, known as insulitis, starts at about 4 weeks of age, resulting in diabetes onset at 12-14 weeks of age in about $60-80 \%$ of female and $10-30 \%$ of male NOD mice [2]. The most important type 1 diabetes susceptibility genes are the MHC genes, in particular MHC Class-II $[3,4]$. In addition, more than 40 non-MHC loci have been identified as contributors to disease susceptibility $[5,6]$. Congenic nonobese-resistant (NOR) mice on the other hand, do not develop diabetes despite sharing $88 \%$ of their genome with NOD mice, including the MHC Class-II haplotype $\mathrm{H}_{2}{ }^{\mathrm{g} 7}$ and other Idd susceptibility genes [7].

The NOD mouse has been used worldwide to investigate the genes, proteins or pathways implicated in type 1 diabetes susceptibility, with a main focus on the role of the immune system [8-12]. However, increasing evidence points towards a role for the beta cells themselves in the initiation of the autoimmune process and attraction/activation of immune cells; however, the exact mechanisms involved remain unclear. Recently, post-translational modifications (PTMs) have been suggested as a mechanism for the generation of autoantigenic epitopes in type 1 diabetes [13,14], as also observed in other autoimmune diseases [14-17]. The aim of this study was to investigate the gene and protein landscape of islets from 2-3-week-old NOD mice compared with islets from NOR and C57Bl/6 mice, with special attention on the presence of PTMs [2].

\section{Materials and methods}

Animals C57Bl/6 mice were obtained from Harlan (Horst, the Netherlands). NOR mice were obtained from Jackson Laboratory (Bar Harbor, ME, USA). NOD mice have been inbred in our animal facility under semi-barrier conditions since 1989. One-week-old and 2-3-week-old mice from mothers that were not diabetic during pregnancy or weaning were used. All animal manipulations were in compliance with the principles of laboratory care and were approved by the Institutional Animal Ethics Committee of KU Leuven.

Islets Islets were isolated as described previously [18]. Briefly, pancreases from ten mice were digested with collagenase and the islets were centrifuged on a dextran gradient and hand-picked to remove exocrine tissue.
RNA isolation and microarray Total RNA from islets of 1week-old and 2-3-week-old NOD, NOR and C57Bl/6 mice (150 islets per extraction, $n=4$ ) was extracted using the RNeasy Micro Kit (Qiagen, Hilden, Germany). Starting from $100 \mathrm{ng}$ of islet RNA, sense-strand DNA was generated and gene expression levels were analysed on Affymetrix GeneChip Mouse Gene 1.0 ST Arrays (for full details see ESM Methods)

Quantitative RT-PCR (qRT-PCR) was performed as described previously [19]. Expression levels of Angptl7, Dpt, Tmem45a, Trnp1, Lbp, Trim12a, Pgap2, Akr1e1, Dio1, Dock10, Vps13d, Lyrm 7 and Padi2 were analysed in islets from 1-week-old and 2-3-week-old NOD, NOR and C57Bl/ 6 mice.

2D-DIGE Samples of $40 \mu \mathrm{g}$ protein lysate, obtained from approximately 1000 islets from 2-3-week-old NOD, NOR and $\mathrm{C} 57 \mathrm{Bl} / 6$ mice $(n=4)$, were separated on immobilized $\mathrm{pH}$ gradient (IPG) strips in $\mathrm{pH}$ range $4-7(24 \mathrm{~cm}$, GE Healthcare, Machelen, Belgium) (full details are available in ESM Methods).

Protein identification Spots were picked from preparative gels with $350 \mu \mathrm{g}$ protein lysate and trypsin digested as described previously [20]. MS analysis was performed by 4800 MALDI-TOF/TOF (Applied Biosystems, Carlsbad, CA, USA) and individual peptides from the MS/MS analysis were manually filtered; those with an individual expected value $>0.05$ were deleted, as were identifications based on a single peptide. Differentially expressed proteins were linked to Idd loci (see ESM Methods for full details).

Network analysis Protein-protein interaction (PPI) networks were created for each list of differentially expressed proteins and first-order neighbours using InWeb [21]. The networks were visualised in Cytoscape [22]. Ranking of the differentially expressed mouse proteins based on their assignment to type 1 diabetes relevant protein complexes was performed as described previously [23]. PANTHER was used to classify genes and proteins by biological processes [24]. Gene ontology (GO) enrichment analysis was performed by AmiGO [25] (full details of these analyses are described in ESM Methods). To identify altered pathways, genes/proteins that were differentially expressed or interacted in a network were loaded into the IPA software and database (Ingenuity Systems, www. ingenuity.com, accessed 1 April 2016). The Mouse Gene 1.0 ST Array reference set was used and all tissues and cell lines were included for analysis.

Statistical analysis Microarray differential expression was calculated using a significance analysis of microarrays (SAM) implemented in the SAMR package. Cut-off values 
were set on false discovery rate (FDR; $q$ value) 0.01 . 2DDIGE analysis was performed by DeCyder software (version 7.2.1.72) and $p \leq 0.05$ was considered significant. The significance of the overlap between differentially expressed genes and proteins, as well as the overlaps between genes and proteins found to be differentially expressed in either NOR or C57Bl/6 islets when compared with NOD islets, was evaluated using a hypergeometric test, considering all protein-coding genes in the mouse genome (GRCm38.p4) as background. See ESM Methods for details. Data are expressed as means \pm SEM and were analysed as stated in figure legends.

\section{Results}

Gene expression profiling in pancreatic islets of prediabetic 2-3-week-old NOD, NOR and C57Bl/6 mice To identify early differences in islets of NOD mice, we performed microarray analyses on islets of 2-3-week-old NOD mice and compared the transcriptome profile to islets of age-matched NOR and $\mathrm{C} 57 \mathrm{~B} 1 / 6$ mice. First, we compared the gene expression between female and male NOD islets (ESM Table 1). Since only five genes, all $\mathrm{X}$ or $\mathrm{Y}$ chromosome linked, were different between both sexes, we decided to focus on islets from female mice only for further investigation. This revealed 213 differentially expressed genes, out of a total of 35,556 genes present on the microarray, between NOD and NOR islets. Of these, 75 had higher and 138 had lower expression levels in NOD islets $(q<0.01)$. Comparison of NOD with $\mathrm{C} 57 \mathrm{Bl} / 6$ islets, revealed a difference in 700 genes $(q<0.01)$; of which, 212 had higher and 488 had lower expression levels in NOD islets (Table 1). Of those, 53 transcripts were differentially regulated when comparing NOD vs NOR and C57Bl/6 $\left(p<1 \times 10^{-10}\right)$ (Fig. 1a, ESM Table 2) No evidence was found for increased expression of IL-1 $\beta$, IFN $\gamma$, TNF $\alpha$ or IL-6 in NOD islets (data not shown), confirming the absence of inflammation in the islets at the time of investigation.

Considering the top five differentially expressed genes in NOD vs NOR islets and NOD vs C57B1/6 islets, Padi 2 was one of the highest ranked, with a 3.40- and 3.09-fold higher expression in NOD islets compared with NOR and C57Bl/6, respectively (Table 1). mRNA expression of Padi2 in agematched NOD.scid islets revealed a similar expression level to NOD, suggesting that transcription happens in endocrine and not immune cells (Fig. 2). qRT-PCR also confirmed the expression levels of other differentially expressed genes at 2 3 weeks of age (ESM Fig. 1), as well as in 1-week-old mice (ESM Fig. 2).

Table 1 Most differentially expressed genes between islets from 2-3-week-old NOD vs NOR and C57Bl/6 mice by microarray

\begin{tabular}{|c|c|c|c|c|c|}
\hline \multirow[t]{2}{*}{ Gene name } & \multirow[t]{2}{*}{ Full gene name } & \multicolumn{2}{|c|}{ NOD vs NOR } & \multicolumn{2}{|c|}{ NOD vs C57Bl/6 } \\
\hline & & $q$ value & $\log _{2}$ fold regulation & $q$ value & $\log _{2}$ fold regulation \\
\hline \multicolumn{6}{|c|}{ Higher expression in NOD islets } \\
\hline Angptl7 & Angiopoietin-like 7 & 0.0000 & $2.26^{* * *}$ & 0.0000 & $2.31^{* * *}$ \\
\hline Padi2 & Peptidyl arginine deiminase, type II & 0.0000 & $1.77^{* * *}$ & 0.0000 & $1.63^{* * *}$ \\
\hline$D p t$ & Dermatopontin & 0.0000 & $2.02^{* * * *}$ & 0.0089 & $1.14^{* *}$ \\
\hline Tmem $45 a$ & Transmembrane protein $45 \mathrm{a}$ & 0.0000 & $0.90^{* * * *}$ & 0.0000 & $1.76^{* * * *}$ \\
\hline$M t 2$ & Metallothionein 2 & 0.0091 & $1.14^{* *}$ & 0.0000 & $1.48^{* * * *}$ \\
\hline Trnpl & TMF1-regulated nuclear protein 1 & 0.0000 & $1.16^{* * * *}$ & 0.0000 & $1.31^{* * * *}$ \\
\hline$L b p$ & Lipopolysaccharide binding protein & 0.0000 & $1.41^{* * * *}$ & 0.0000 & $1.03^{* * * *}$ \\
\hline Penk & Preproenkephalin & 0.0000 & $1.38^{* * *}$ & 0.0089 & $0.90^{* *}$ \\
\hline \multicolumn{6}{|c|}{ Lower expression in NOD islets } \\
\hline $\operatorname{Trim} 12 a$ & Tripartite motif-containing $12 \mathrm{~A}$ & 0.0000 & $-1.77^{* * * *}$ & 0.0000 & $-2.44^{* * * *}$ \\
\hline Pgap2 & Post-GPI attachment to proteins 2 & 0.0000 & $-1.27^{* * *}$ & 0.0000 & $-1.68^{* * * *}$ \\
\hline Akrlel & Aldo-keto reductase family 1, member E1 & 0.0000 & $-1.04^{* * * *}$ & 0.0000 & $-1.49^{* * * *}$ \\
\hline Diol & Deiodinase, iodothyronine, type I & 0.0000 & $-1.07^{* * * *}$ & 0.0000 & $-1.45^{* * * *}$ \\
\hline Dock10 & Dedicator of cytokinesis 10 & 0.0000 & $-1.25^{* * *}$ & 0.0028 & $-1.22^{* *}$ \\
\hline $\operatorname{Lrp} 8$ & $\begin{array}{l}\text { Low density lipoprotein receptor-related protein } 8 \text {, } \\
\text { apolipoprotein e receptor }\end{array}$ & 0.0000 & $-1.42^{* * *}$ & 0.0000 & $-0.98^{* * *}$ \\
\hline Vps13d & Vacuolar protein sorting $13 \mathrm{D}$ (yeast) & 0.0000 & $-1.13^{* * * *}$ & 0.0028 & $-0.64^{* *}$ \\
\hline Lyrm7 & LYR motif-containing 7 & 0.0000 & $-1.09^{* * *}$ & 0.0046 & $-0.53^{* *}$ \\
\hline
\end{tabular}

$n=4$ independent experiments

Significant fold regulations have at least a 1.3 -fold change $\left(0.38 \log _{2}\right.$ fold change $)$ in expression and an FDR of 0.01

$* * q<0.01 ; * * * q<0.001$ 
GO classification of the differentially expressed genes in NOD vs NOR and C57B1/6 islets (ESM Tables 3, 4) revealed a prominent prevalence of transcripts implicated in biological pathways related to metabolic processes $(50.0 \%$ and $45.1 \%$ of all differentially expressed transcripts compared with NOR or C57Bl/6, respectively), especially primary metabolic processes, and cellular processes $(39.7 \%$ and $39.3 \%$ compared with NOR or C57Bl/6, respectively), with the majority involved in cell communication. Genes that are differentially expressed in NOD islets compared with both NOR and C57B1/6 represented the same groups (ESM Table 5). Further enrichment analysis of the differential genes in NOD vs C57Bl/6 islets (ESM Table 6) highlighted genes associated with carbohydrate derivative transport (7.79-fold; $p=2.71 \times 10^{-2}$ ), response to metal ions (3.38-fold; $p=2.84 \times 10^{-2}$ ) and regulation of protein kinase activity (2.49-fold enriched compared with $\mathrm{C} 57 \mathrm{Bl} / 6$; $p=4.47 \times 10^{-4}$ ) (Fig. 3), with the expression of the majority of genes being lower in NOD islets.

To investigate how the differentially expressed genes in NOD islets connect to each other, PPI network analysis was performed. Among the 213 differentially expressed genes in NOD vs NOR islets, 101 genes clustered together within the PPI network and formed a significant $\left(p=3.79 \times 10^{-6}\right)$ subnetwork with inclusion of first-order interaction partners, resulting in a total of 497 genes with 702 interactions. The genes differentially expressed in NOD vs C57Bl/6 islets were significantly connected $\left(p=2.42 \times 10^{-3}\right)$, in a subnetwork containing 363 input genes, extended to 1408 genes when including first-order interaction partners and containing 3298 interactions in between. Furthermore, as for the differentially expressed genes, there was a significant overlap of 88 genes when comparing the NOD vs NOR and NOD vs C57Bl/6 networks $\left(p=1.38 \times 10^{-8}\right)$ (Fig. 1b).

Ingenuity pathway analysis (IPA) of the identified PPI networks revealed that both in the NOD vs NOR and NOD vs C57Bl/6 network (ESM Tables 7, 8), genes related to endocrine system development were highly represented. In
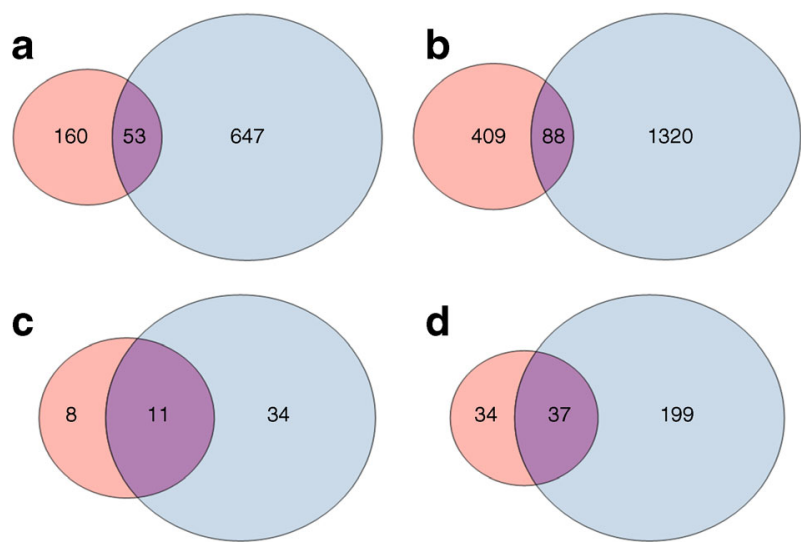

Fig. 1 Overlap between NOD vs NOR (pink) and NOD vs C57Bl/6 (blue) differentially expressed (a) genes and (c) proteins and respective networks (b) and (d). Overlap, $p<0.05$

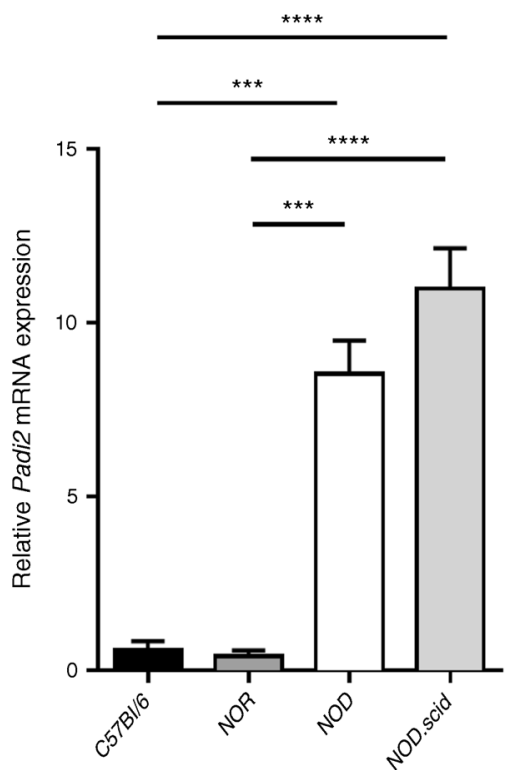

Fig. 2 Padi2 mRNA is highly expressed in 2-3-week-old NOD and NOD.scid islets compared with $\mathrm{C} 57 \mathrm{Bl} / 6$ and NOR islets. Statistical analysis was performed by one-way ANOVA. $n=4-10$; $* * * p<0.001 ; * * * * p<0.0001$

addition, the NOD vs $\mathrm{C} 57 \mathrm{Bl} / 6$ network was enriched for genes functioning in carbohydrate metabolism, as well as genes related to cellular movement, cell death and survival. In general, the functional networks identified by IPA were clearly related to the ontological classes that were assigned to the differentially expressed genes by PANTHER and AmiGO, as described above. When evaluating potential upstream regulators by IPA, a significant number of genes were linked to predicted lower expression of Hnfla in NOD islets compared with both control groups (Fig. 4a,b), which was confirmed by qRT-PCR (Fig. 4c).

Proteomic profiling in pancreatic islets of prediabetic 2-3week-old NOD vs NOR and C57Bl/6 mice In parallel to the microarray analysis, differences in the proteome of NOD vs NOR and $\mathrm{C} 57 \mathrm{Bl} / 6$ islets were investigated by 2D-DIGE. Of the $2141 \pm 186$ spots detected, 124 spots showed a differential expression between at least two groups $(n=4, p<0.05)$ (Fig. 5). Of these, 89 unique proteins were identified (identification rate $65 \%$ ). Similar to the transcriptome analysis, most significant differences were observed between NOD vs C57Bl/6 islets (100 protein spots, 45 proteins identified), while the islet-proteome of the congenic NOR mice only had 39 differential protein spots (19 proteins identified) (Table 2). Eleven proteins were differentially expressed in NOD compared with both $\mathrm{C} 57 \mathrm{Bl} / 6$ and NOR islets $\left(p<1 \times 10^{-10}\right)$ (Fig. 1c, ESM Table 9)

GO classification of the differentially expressed proteins in NOD compared with NOR and $\mathrm{C} 57 \mathrm{Bl} / 6$ islets demonstrated a high prevalence of the same biological processes as in the transcriptome analysis, namely 
Fig. 3 GO classification of differentially expressed genes in NOD vs C57Bl/ 6 islets showed enrichment of the biological pathways related to

(a) carbohydrate derivative transport (GO: 1901264) (7.79-fold enriched; $\left.p=2.71 \times 10^{-2}\right),(\mathbf{b})$ response to metal ions (GO: 0010038) (3.38-fold enriched; $p=2.84 \times 10^{-2}$ ) and (c) regulation of protein kinase activity (GO: 0045859) (2.49-fold enriched; $\left.p=4.47 \times 10^{-4}\right)$. Genes that are linked to these classes are shown and expression levels in NOD vs C57Bl/6 islets are represented ( $>1.3$-fold higher, green; 1.3-2.5-fold lower, orange; $>2.5$-fold lower, red). Analysis performed by AmiGO

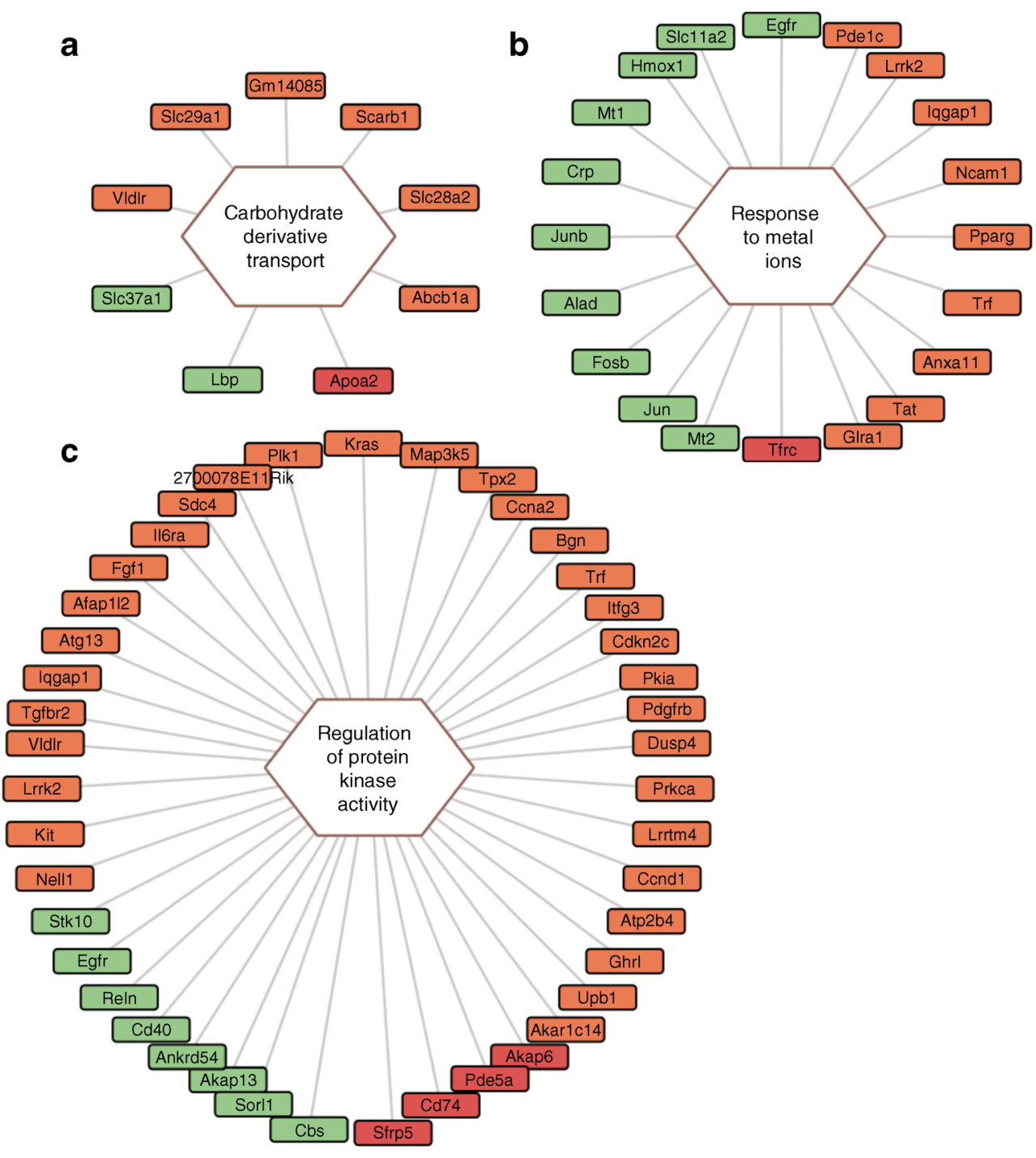

metabolic processes $(60.9 \%$ and $52.6 \%$, respectively) and cellular processes $(30.4 \%$ and $42.1 \%$, respectively). Furthermore, the majority of proteins that were shared by NOR and $\mathrm{C} 57 \mathrm{Bl} / 6$ islets, but different in NOD, were related to metabolic $(50 \%)$ and cellular processes $(62.5 \%)$. Although the data set of differentially expressed proteins is relatively small, significant enrichment of proteins implicated in protein folding $\left(p=3.65 \times 10^{-4}\right)$, more specifically in positive regulation of protein folding $\left(p=2.90 \times 10^{-4}\right)$, was differential in NOD vs C57Bl/6 islets (Fig. 6). In the latter group, the expression of protein disulfide-isomerase A3 (PDIA3), PDIA4 and heat shock cognate $71 \mathrm{kDa}$ protein (HSP7C) was lower in NOD islets.

PPI networks were generated based on differentially expressed proteins in NOD islets and first-order interaction partners, similarly as for the transcriptome analysis. Out of the 39 differentially expressed proteins between NOD and
NOR islets, 13 formed a significant $\left(p=1.10 \times 10^{-5}\right)$ network, which was increased to 71 proteins and 80 internal interactions when including first-order interaction partners. Twentynine differentially expressed proteins between NOD and $\mathrm{C} 57 \mathrm{Bl} / 6$ formed a connected network $\left(p=4.96 \times 10^{-6}\right)$, which increased to 236 proteins and 436 internal interactions including the first-order interaction partners. Comparison of the two networks revealed 37 shared proteins $\left(p<10 \times 10^{-10}\right)$ (Fig. 1d); of which, most were linked to a subnetwork clustered around PDIA3, ezrin (EZR) and inner membrane protein, mitochondrial (IMMT) (Fig. 7).

2D-DIGE analysis revealed that 29\% (26/89) of the identified islet proteins were present in multiple isoforms. Seven proteins showed a shift in abundance between two isoforms between NOD and C57B1/6 mice (Table 3). Among these were two chaperones, the endoplasmic reticulum (ER) chaperone glucose-regulated protein of $78 \mathrm{kDa}$ (GRP78) and the mitochondrial stress protein (GRP75). Three of the PTM proteins were 
a

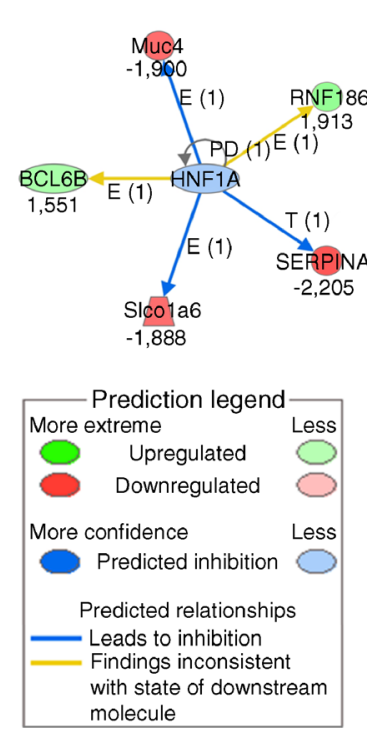

Fig. 4 Expression of Hnfla is predicted to be inhibited in (a) NOD vs NOR and (b) NOD vs C57Bl/6 islets by IPA, based on the expression levels of downstream differentially expressed genes. The genes and arrows are coloured according to expression levels, confidence and

enzymes, namely hydrolase $3^{\prime}\left(2^{\prime}\right), 5^{\prime}$-bisphosphate nucleotidase 1 (BPNT1), mitochondrial phosphoenolpyruvate carboxykinase [GTP] (PCKGM) with a role in gluconeogenesis and arsenite methyltransferase (AS3MT). The latter was present in four different isoforms; of which, expression in NOD was higher in one and lower in three compared with $\mathrm{C} 57 \mathrm{Bl} / 6$ islets. Annexin A5 (ANXA5) and UDP- $N$-acetylhexosamine pyrophosphorylase-like protein 1 (UAP1L) were both predicted relationship. (c) Lower mRNA expression in NOD islets was confirmed by qRT-PCR. Statistical analysis was performed by one-way ANOVA. $n=4 ; * p<0.05$

present in two isoforms; of which, one was more and one less abundant in NOD compared with C57B1/6 islets.

A challenge when analysing the differences between NOD and healthy control islets is to identify the proteins that are relevant to the disease pathogenesis. For this purpose, we performed gene prioritisation by ranking differentially expressed islet proteins according to their potential relevance to type 1 diabetes based on text mining of biomedical records
Fig. 5 2D-gel image with indication of differentially expressed protein spots in NOD vs NOR $(n=39)$ and NOD vs C57Bl/6 islets $(n=100)$. Analysis performed by Decyder version 7.2.1.72. $n=4 ; p<0.05$

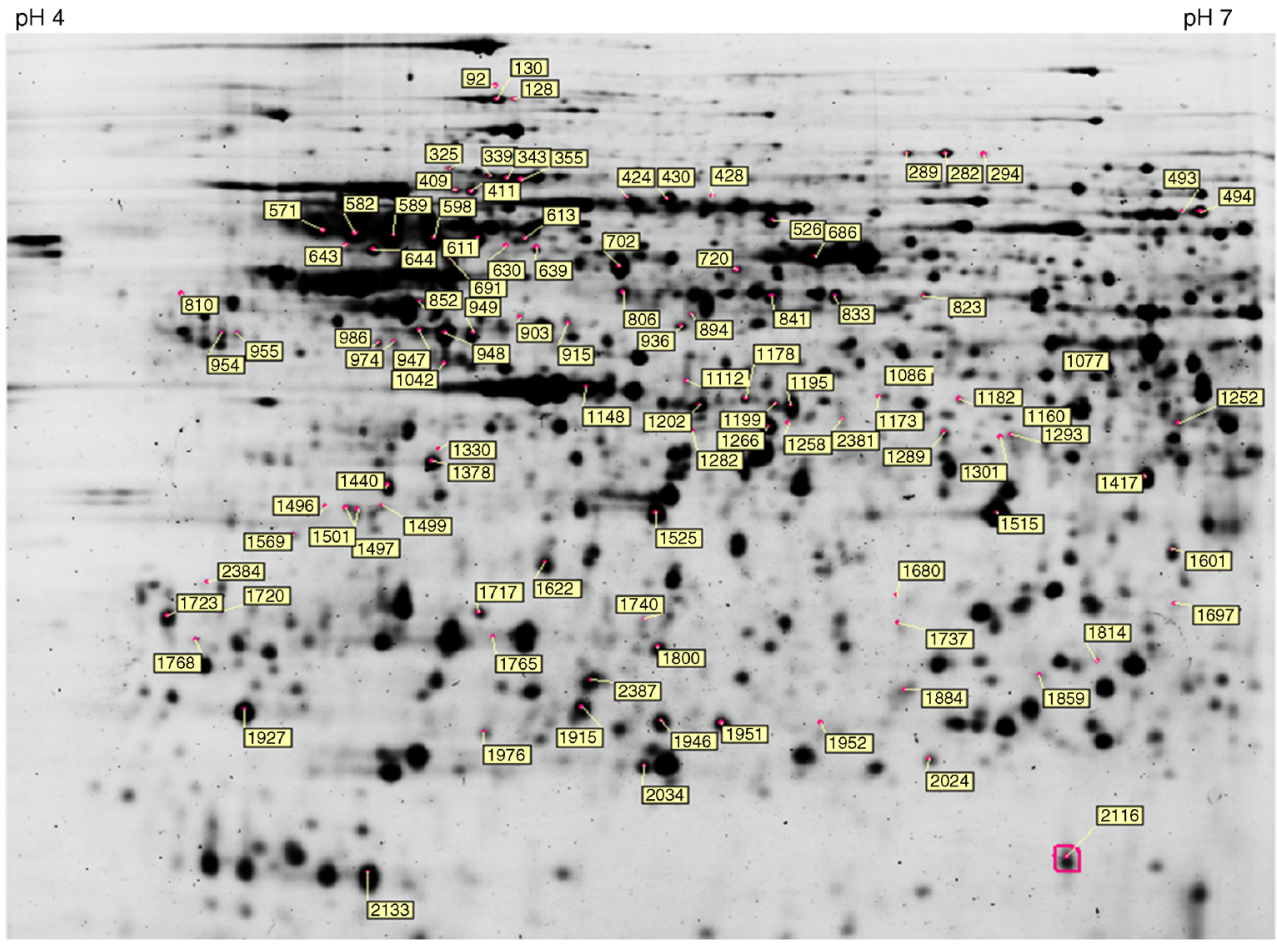


Table 2 Differentially expressed identified proteins between islets from 2-3-week-old NOD vs NOR and NOD vs C57Bl/6 mice by 2D-DIGE and MALDI-TOF/TOF

\begin{tabular}{|c|c|c|c|c|c|c|}
\hline \multirow{2}{*}{$\begin{array}{l}\text { Protein } \\
\text { symbol }\end{array}$} & \multirow{2}{*}{$\begin{array}{l}\text { UniProt acc. } \\
\text { no. }\end{array}$} & \multicolumn{2}{|c|}{ NOD vs NOR } & \multicolumn{2}{|c|}{ NOD vs C57Bl/6 } & \multirow{2}{*}{$\begin{array}{l}\text { Number of peptides } \\
\text { sequenced }\end{array}$} \\
\hline & & $t$ test & $\begin{array}{l}\text { Fold } \\
\text { regulation }\end{array}$ & $t$ test & $\begin{array}{l}\text { Fold } \\
\text { regulation }\end{array}$ & \\
\hline TERA & Q01853 & 0.015 & $1.26^{*}$ & 0.099 & 1.22 & 5 \\
\hline TERA & Q01853 & 0.014 & $1.78^{*}$ & 0.075 & 1.4 & 5 \\
\hline IMMT & Q8CAQ8 & 0.010 & $1.34^{*}$ & 0.00025 & $1.5^{* * * *}$ & 7 \\
\hline EZRI & P26040 & 0.20 & 1.17 & 0.025 & $1.25^{*}$ & 2 \\
\hline EZRI & P26040 & 0.0054 & $1.37^{* *}$ & 0.017 & $1.58^{*}$ & 2 \\
\hline GRP78 & P20029 & 0.15 & 1.80 & 0.030 & $2.14^{*}$ & 12 \\
\hline DC1I2 & O88487 & 0.046 & $1.63^{*}$ & 0.019 & $1.86^{*}$ & 4 \\
\hline NDUS1 & Q91VD9 & 0.046 & $1.63^{*}$ & 0.019 & $1.86^{*}$ & 3 \\
\hline NDUS1 & Q91VD9 & 0.031 & $1.32^{*}$ & 0.077 & 1.43 & 7 \\
\hline DC1I2 & O88487 & 0.031 & $1.59^{*}$ & 0.020 & $1.68^{*}$ & 3 \\
\hline NDUS1 & Q91VD9 & 0.031 & $1.59^{*}$ & 0.020 & $1.68^{*}$ & 4 \\
\hline GRP78 & P20029 & 0.11 & -2.18 & 0.022 & $-4.04^{*}$ & 2 \\
\hline PDIA4 & P08003 & 0.11 & -2.18 & 0.022 & $-4.04^{*}$ & 5 \\
\hline HSP7C & P63017 & 0.22 & -1.70 & 0.022 & $-3.04^{*}$ & 2 \\
\hline PDIA4 & P08003 & 0.22 & -1.70 & 0.022 & $-3.04^{*}$ & 5 \\
\hline VATA & P50516 & 0.19 & -1.18 & 0.017 & $-2.09^{*}$ & 6 \\
\hline GRP75 & P38647 & 0.23 & -1.27 & $1.0 \times 10^{-5}$ & $6.36^{* * * *}$ & 7 \\
\hline GRP75 & P38647 & 0.23 & -1.17 & 0.00029 & $-3.26^{* * *}$ & 4 \\
\hline PCKGM & Q8BH04 & 0.21 & 1.61 & 0.0017 & $3.15^{* * *}$ & 5 \\
\hline PCKGM & Q8BH04 & 0.82 & -1.03 & 0.019 & $-2.59^{*}$ & 2 \\
\hline ODP2 & Q8BMF4 & 0.024 & $1.56^{*}$ & 0.22 & 1.29 & 6 \\
\hline $\mathrm{NEC} 2$ & P21661 & 0.096 & 1.27 & 0.035 & $2.33^{*}$ & 3 \\
\hline $\mathrm{NEC} 2$ & P21661 & 0.038 & $1.35^{*}$ & 0.014 & $3.2^{*}$ & 3 \\
\hline NEC2 & P21661 & 0.083 & 1.28 & 0.014 & $3.38^{*}$ & 5 \\
\hline HNRPK & P61979 & 0.14 & 1.31 & 0.019 & $3.09^{*}$ & 9 \\
\hline NEC2 & P21661 & 0.14 & 1.31 & 0.019 & $3.09^{*}$ & 4 \\
\hline HNRPK & P61979 & 0.42 & 1.2 & 0.011 & $2.36^{*}$ & 4 \\
\hline UAP1L & Q3TW96 & 0.20 & 1.94 & 0.0055 & $4.84^{* * *}$ & 5 \\
\hline UAP1L & Q3TW96 & 0.87 & 1.03 & 0.0089 & $-2.52^{* *}$ & 6 \\
\hline PDIA3 & P27773 & 0.036 & $-1.99^{*}$ & 0.046 & $-2.11^{*}$ & 3 \\
\hline CH60 & P63038 & 0.047 & $-1.63^{*}$ & 0.15 & -1.36 & 11 \\
\hline DPP2 & Q9ET22 & 0.85 & -1.03 & 0.041 & $2.67^{*}$ & 3 \\
\hline GORS2 & Q99JX3 & 0.85 & -1.03 & 0.041 & $2.67^{*}$ & 3 \\
\hline RUVB2 & Q9WTM5 & 0.045 & $1.36^{*}$ & 0.47 & 1.1 & 12 \\
\hline KAP0 & Q9DBC7 & 0.0011 & $-2.44^{* *}$ & 0.045 & $-2.16^{*}$ & 9 \\
\hline KAP0 & Q9DBC7 & 0.019 & $-1.41^{*}$ & 0.0032 & $-1.69^{* *}$ & 10 \\
\hline GSHB & P51855 & 0.019 & $1.68^{*}$ & 0.14 & 1.58 & 2 \\
\hline PDIA6 & Q922R8 & 0.0086 & $-3.03^{* *}$ & 0.028 & $-4.55^{*}$ & 5 \\
\hline PDIA6 & Q922R8 & 0.0014 & $-2.68^{* *}$ & 0.011 & $-2.76^{*}$ & 3 \\
\hline PRS6A & O88685 & 0.063 & 2.19 & 0.021 & $2.88^{*}$ & 10 \\
\hline SCG3 & P47867 & 0.34 & -1.24 & 0.027 & $-2.69^{*}$ & 5 \\
\hline SCG3 & P47867 & 0.44 & -1.15 & 0.028 & $-2.19^{*}$ & 3 \\
\hline ENOG & P17183 & 0.26 & -1.42 & 0.020 & $1.76^{*}$ & 2 \\
\hline ERP44 & Q9D1Q6 & 0.0089 & $-1.44^{* *}$ & 0.75 & -1.08 & 8 \\
\hline NSF1C & Q9CZ44 & 0.0089 & $-1.44^{* *}$ & 0.75 & -1.08 & 2 \\
\hline SAHH & P50247 & 0.26 & 1.25 & 0.0083 & $-2.33^{* *}$ & 9 \\
\hline CMPK2 & Q3U5Q7 & 0.47 & 1.13 & 0.0066 & $1.68^{* *}$ & 3 \\
\hline
\end{tabular}


Table 2 (continued)

\begin{tabular}{|c|c|c|c|c|c|c|}
\hline \multirow{2}{*}{$\begin{array}{l}\text { Protein } \\
\text { symbol }\end{array}$} & \multirow{2}{*}{$\begin{array}{l}\text { UniProt acc. } \\
\text { no. }\end{array}$} & \multicolumn{2}{|c|}{ NOD vs NOR } & \multicolumn{2}{|c|}{ NOD vs C57Bl/6 } & \multirow{2}{*}{$\begin{array}{l}\text { Number of peptides } \\
\text { sequenced }\end{array}$} \\
\hline & & $t$ test & $\begin{array}{l}\text { Fold } \\
\text { regulation }\end{array}$ & $t$ test & $\begin{array}{l}\text { Fold } \\
\text { regulation }\end{array}$ & \\
\hline KCRB & Q04447 & 0.86 & -1.11 & 0.044 & $-2.28^{*}$ & 4 \\
\hline AS3MT & Q91WU5 & 0.97 & -1.01 & 0.019 & $1.85^{*}$ & 3 \\
\hline AS3MT & Q91WU5 & 0.50 & -1.14 & $6.6 \times 10^{-6}$ & $-6.08^{* * * *}$ & 2 \\
\hline CATD & P18242 & 0.019 & $1.5^{*}$ & 0.087 & 1.63 & 3 \\
\hline GNAO & P18872 & 0.019 & $1.5^{*}$ & 0.087 & 1.63 & 4 \\
\hline BPNT1 & Q9Z0S1 & 0.53 & 1.13 & 0.041 & $-1.95^{*}$ & 2 \\
\hline EIF3H & Q91WK2 & 0.045 & $1.52^{*}$ & 0.32 & 1.19 & 5 \\
\hline BPNT1 & Q9Z0S1 & 0.33 & 1.43 & 0.00070 & $8.44^{* * * *}$ & 3 \\
\hline BPNT1 & Q9Z0S1 & 0.30 & -2.28 & 0.00029 & $-18.14^{* * * *}$ & 8 \\
\hline BPNT1 & Q9Z0S1 & 0.28 & -1.72 & 0.00033 & $-3.69^{* * * *}$ & 3 \\
\hline GNAQ & P21279 & 0.28 & -1.72 & 0.00033 & $-3.69^{* * * *}$ & 3 \\
\hline DCPS & Q9DAR7 & 0.32 & 1.17 & 0.039 & $1.64^{*}$ & 4 \\
\hline CSN5 & O35864 & 0.20 & 1.3 & 0.022 & $1.69^{*}$ & 4 \\
\hline DCPS & Q9DAR7 & 0.20 & 1.3 & 0.022 & $1.69^{*}$ & 3 \\
\hline IF2A & Q6ZWX6 & 0.017 & $-1.48^{*}$ & 0.23 & 1.13 & 7 \\
\hline $\mathrm{AK} 1 \mathrm{CD}$ & Q8VC28 & 0.069 & 1.26 & 0.017 & $1.34^{*}$ & 5 \\
\hline TXNL1 & Q8CDN6 & 0.54 & -1.06 & 0.037 & $1.41^{*}$ & 8 \\
\hline ANXA5 & P48036 & 0.26 & -1.56 & 0.0021 & $2.05^{* *}$ & 7 \\
\hline COPE & O89079 & 0.039 & $-1.65^{*}$ & 0.13 & 1.25 & 2 \\
\hline EF1D & P57776 & 0.93 & 1.01 & 0.0062 & $-2.23^{* *}$ & 2 \\
\hline EF1D & P57776 & 0.85 & -1.02 & 0.019 & $-2.57^{*}$ & 5 \\
\hline $5 \mathrm{NT3}$ & Q9D020 & 0.27 & 1.13 & 0.044 & $1.66^{*}$ & 5 \\
\hline ANXA5 & P48036 & 0.079 & -2.79 & 0.048 & $-4.3^{*}$ & 2 \\
\hline NMRL1 & Q8K2T1 & 0.84 & 1.02 & 0.0078 & $1.68^{* *}$ & 3 \\
\hline GLOD4 & Q9CPV4 & 0.56 & -1.06 & 0.00085 & $-2.59^{* * *}$ & 4 \\
\hline ERP29 & P57759 & 0.60 & 1.3 & 0.0014 & $10.62^{* *}$ & 5 \\
\hline CNPY2 & Q9QXT0 & 0.60 & 1.3 & 0.0014 & $10.62^{* *}$ & 2 \\
\hline HDHD3 & Q9CYW4 & 0.48 & 1.11 & 0.017 & $1.7^{*}$ & 2 \\
\hline $1433 \mathrm{E}$ & P62259 & 0.80 & 1.06 & 0.035 & $1.5^{*}$ & 6 \\
\hline ERP29 & P57759 & 0.45 & -1.53 & 0.017 & $2.92^{*}$ & 3 \\
\hline IF4E & P63073 & 0.45 & -1.53 & 0.017 & $2.92^{*}$ & 2 \\
\hline CLIC4 & Q9QYB1 & 0.54 & -1.14 & 0.0030 & $-1.64^{* *}$ & 7 \\
\hline $\mathrm{LXN}$ & P70202 & 0.54 & -1.14 & 0.0030 & $-1.64^{* *}$ & 2 \\
\hline CO038 & Q9D0A3 & 0.0060 & $-1.82^{* *}$ & 0.024 & $-1.83^{*}$ & 4 \\
\hline HMGB1 & P63158 & 0.097 & -1.29 & 0.0071 & $-1.43^{* *}$ & 7 \\
\hline RMD1 & Q9DCV4 & 0.097 & -1.29 & 0.0071 & $-1.43^{* *}$ & 2 \\
\hline PRDX6 & O08709 & 0.046 & $-1.42^{*}$ & 0.26 & 1.12 & 2 \\
\hline ТСТР & P63028 & 0.16 & -1.99 & 0.019 & $1.63^{*}$ & 6 \\
\hline PSB4 & P99026 & 1 & -1.01 & 0.044 & $1.69^{*}$ & 6 \\
\hline ABHEB & Q8VCR7 & 0.90 & 1.02 & 0.0016 & $3.63^{* * *}$ & 5 \\
\hline COF1 & P18760 & 0.69 & 1.09 & 0.0039 & $2.2^{* * *}$ & 2 \\
\hline CMGA & P26339 & 0.30 & -1.78 & 0.030 & $-3.73^{*}$ & 5 \\
\hline KAD1 & Q9R0Y5 & 0.0062 & $-2.12^{* *}$ & 0.00029 & $-2.58^{* * * *}$ & 2 \\
\hline TPM3 & P21107 & 0.0044 & $-1.4^{* *}$ & 0.040 & $-1.4^{*}$ & 4 \\
\hline AIBP & Q8K4Z3 & 0.91 & -1.1 & 0.0078 & $-1.98^{* *}$ & 2 \\
\hline
\end{tabular}

$n=4$ independent experiments

Significant fold regulations are indicated by $* p<0.05 ; * * p<0.01 ; * * * p<0.001$ 


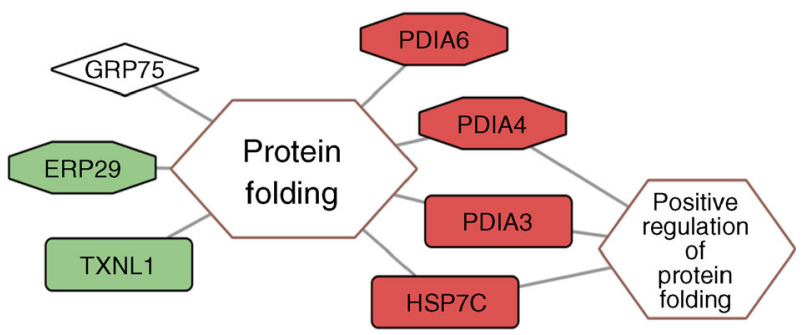

Fig. 6 GO classification of differentially expressed proteins in NOD vs $\mathrm{C} 57 \mathrm{Bl} / 6$ islets showed enrichment of the biological pathways related to protein folding (GO: 0006457) $\left(p=3.65 \times 10^{-4}\right)$ and more specifically positive regulation of protein folding (GO: 1903334) $\left(p=2.90 \times 10^{-4}\right)$. Proteins linked to these classes are shown and expression levels in NOD compared with $\mathrm{C} 57 \mathrm{Bl} / 6$ islets are presented (higher expression, green; lower expression, red). The label shape indicates the presence in multiple isoforms (octagon, same regulation; diamond, differential regulation). GO analysis performed by AmiGO

from the OMIM and PubMed databases (Tables 4, 5). This pointed to an important role for PDIAs. PDIA3, which was differentially expressed both in NOD vs NOR and NOD vs $\mathrm{C} 57 \mathrm{Bl} / 6$, was the highest ranked protein with regard to type 1 diabetes relevance in both comparisons. In addition, PDIA4, which was only significantly differentially expressed between $\mathrm{NOD}$ vs $\mathrm{C} 57 \mathrm{Bl} / 6$, was also ranked in the top ten in this comparison. Finally, PDIA6, which had lower expression in NOD compared with both NOR and C57B1/6 islets, was also retrieved as a relevant candidate protein, ranked in the top ten.

Another highly ranked protein involved in protein metabolism was neuroendocrine convertase 2 (NEC2). This endopeptidase, mediating the conversion of proinsulin to insulin in beta cells, had one isoform that had significantly higher expression in NOD vs NOR islets, while four isoforms were higher in NOD compared with C57Bl/6 islets (Table 3).

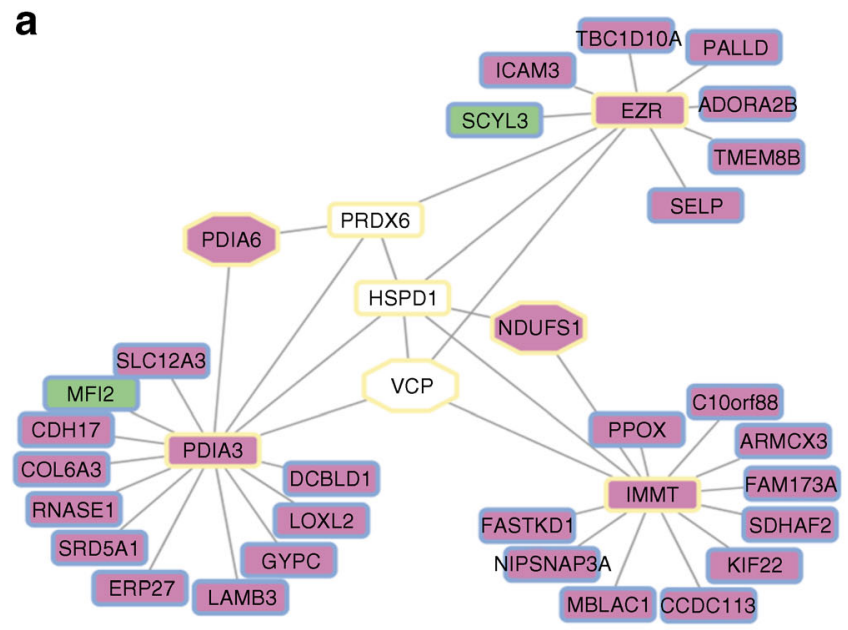

Fig. 7 Detail of the PPI network of differentially expressed proteins (yellow border) and first-order interaction partners (blue border) in (a) NOD vs NOR and (b) NOD vs C57Bl/6 islets. Proteins that overlap between NOD vs NOR and NOD vs C57B1/6 network are shown in
Several cytoskeletal proteins appeared in the top ten proteins associated with type 1 diabetes (Tables 4, 5). As such, tropomyosin alpha-3 chain (TPM3), important for the stabilisation of actin filaments, had lower expression in NOD islets. In contrast, ezrin (EZR), connecting cytoskeleton structures such as actin and microtubules to the plasma membrane, was more highly expressed in NOD islets.

\section{Discussion}

In this study, we aimed to identify early differences in islets of NOD mice compared with congenic NOR and wild-type C57Bl/6 mice by the combination of transcriptional and translational analysis. Although several studies have been performed to characterise diabetes predisposing genes and proteins, most of them have focused on the role of the immune system in this process instead of the islets themselves [8-12, 26] or expression levels of only mRNA [9] or proteins [27] were investigated.

For high-throughput analysis of gene expression levels, microarrays are very appropriate because of their high sensitivity and accuracy. However, mRNA levels do not always correlate with respective protein levels, which are much more relevant to the biological function of cells. For that reason, we combined microarray with proteome analysis by 2D-DIGE. Although this technique also has some constraints, such as limited detection of proteins with low abundance, extreme isoelectric point or high hydrophobicity, an enormous advantage of 2D-DIGE is the possibility to detect the occurrence of PTMs even without knowing the nature of the modification.

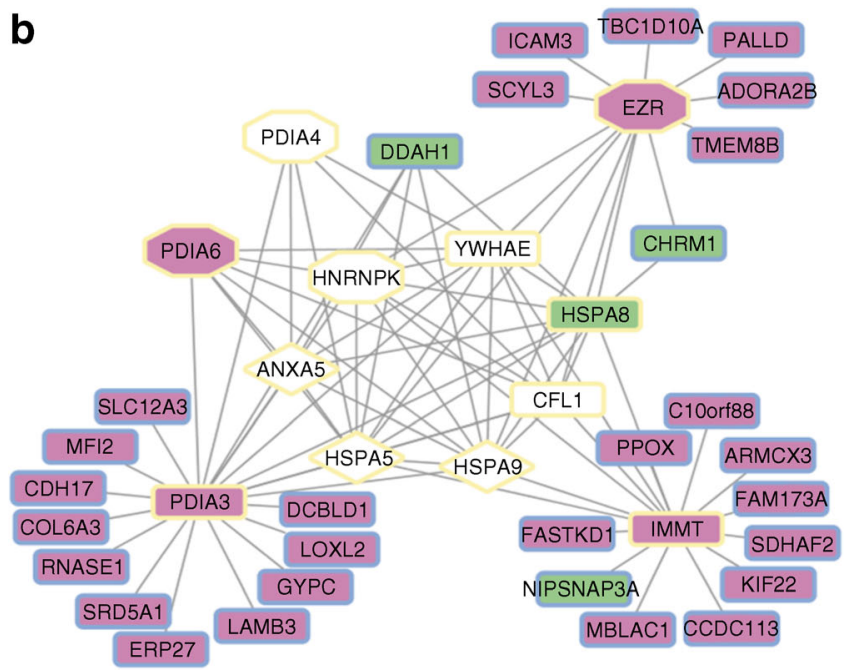

purple. Proteins with differential mRNA expression are shown in green. The label shape indicates the presence in multiple isoforms (octagon, same regulation; diamond, differential regulation) 
Table 3 Differentially regulated PTM proteins between islets from NOD vs C57B1/6 islets by 2D-DIGE

\begin{tabular}{lcllll}
\hline $\begin{array}{l}\text { Spot } \\
\text { no. }\end{array}$ & Protein name & $\begin{array}{l}\text { Protein } \\
\text { symbol }\end{array}$ & $\begin{array}{l}\text { UniProt } \\
\text { acc. no. }\end{array}$ & $p$ value & $\begin{array}{l}\text { Fold } \\
\text { regulation }\end{array}$ \\
\hline 493 & Phosphoenolpyruvate carboxykinase & PCKGM & Q8BH04 & 0.0017 & 3.15 \\
494 & {$[\mathrm{GTP}$. mitochondrial } & & & 0.019 & -2.59 \\
630 & UDP- $N$-acetylhexosamine & UAP1L & Q3TW96 & 0.0055 & 4.84 \\
639 & pyrophosphorylase-like protein 1 & & & 0.0089 & -2.52 \\
1199 & $3^{\prime}\left(2^{\prime}\right), 5^{\prime}$-Bisphosphate nucleotidase 1 & BPNT1 & Q9Z0S1 & 0.041 & -1.95 \\
1258 & & & 0.00070 & 8.44 \\
1266 & & & 0.00029 & -18.14 \\
1282 & & & 0.00033 & -3.69 \\
325 & 78 kDa glucose-regulated protein & GRP78 & P20029 & 0.030 & 2.14 \\
409 & & & & 0.022 & -4.04 \\
428 & Stress-70 protein. mitochondrial & GRP75 & P38647 & $1.0 \times 10^{-4}$ & 6.36 \\
430 & & & & 0.00029 & -3.26 \\
1173 & Arsenite methyltransferase & AS3MT & Q91WU5 & 0.019 & 1.85 \\
1178 & & & & $6.6 \times 10^{-6}$ & -6.08 \\
1496 & Annexin A5 & ANXA5 & P48036 & 0.0021 & 2.05 \\
1569 & & & & 0.048 & -4.30 \\
\hline
\end{tabular}

$n=4$ independent experiments
In addition to the combination of both techniques, this study was completed by performing integrated data analyses, making use of PPI networks, pathway analyses by IPA, PANTHER and AmiGO, and in silico gene prioritisation for type 1 diabetes relevance.

Since diabetes incidence is known to be higher in female NOD mice compared with males, microarray was performed to identify sex-differences that contribute to diabetes predisposition. The expression of only five genes, all $\mathrm{X}$ or $\mathrm{Y}$ chromosome linked, was different between NOD males and females (ESM Table 1). Therefore, only female mice were used for further investigations. C57Bl/6 mice and NOR mice that display insulitis without the development of diabetes were both used as control strains. Analysis of genes and proteins that are differentially expressed in NOD islets compared with both control strains indicated that there were 53 common genes (ESM Table 3) and 11 common proteins (ESM Table 4). Six of these proteins (TPM3,

Table 4 Gene prioritisation of differentially expressed proteins between NOD vs NOR islets: ten highest ranked proteins

\begin{tabular}{|c|c|c|c|c|c|c|c|c|}
\hline \multirow[t]{2}{*}{ Spot no. } & \multirow[t]{2}{*}{ Protein name } & \multirow[t]{2}{*}{ Protein symbol } & \multirow[t]{2}{*}{ UniProt acc. no. } & \multicolumn{2}{|c|}{ OMIM } & \multicolumn{2}{|c|}{ PubMed } & \multirow[b]{2}{*}{ Average rank } \\
\hline & & & & Rank & Top partner & Rank & Top partner & \\
\hline $128 ; 130$ & Transitional endoplasmic reticulum ATPase & TERA & Q01853 & 3 & SUMO4 & 1 & SUMO4 & 2 \\
\hline 686 & Protein disulfide-isomerase A3 & PDIA3 & P27773 & 2 & SUMO4 & 2 & SUMO4 & 2 \\
\hline 2384 & Tropomyosin alpha-3 chain & TPM3 & P21107 & 1 & SUMO4 & 5 & SUMO4 & 3 \\
\hline 582 & Neuroendocrine convertase 2 & NEC2 & P21661 & 6 & IAPP & 4 & IAPP & 5 \\
\hline $903 ; 915$ & $\begin{array}{l}\text { cAMP-dependent protein kinase type I-alpha } \\
\text { regulatory subunit }\end{array}$ & KAP0 & Q9DBC7 & 10 & HLA-A & 3 & HLA-A & 6.5 \\
\hline 1884 & Peroxiredoxin-6 & PRDX6 & O08709 & 7 & SUMO4 & 7 & SUMO4 & 7 \\
\hline 294 & Ezrin & EZRI & P26040 & 9 & HLA-B & 6 & HLA-B & 7.5 \\
\hline 2381 & Adenylate kinase isoenzyme 1 & KAD1 & Q9R0Y5 & 5 & PPP1R3A & 12 & PPP1R3A & 8.5 \\
\hline $947 ; 948$ & Protein disulfide-isomerase A6 & PDIA6 & Q922R8 & 4 & SUMO4 & 14 & SUMO4 & 9 \\
\hline 936 & Glutathione synthetase & GSHB & P51855 & 8 & ТР63 & 11 & GSTZ1 & 9.5 \\
\hline
\end{tabular}

Human orthologues of mouse genes were assigned to type 1 diabetes relevant protein complexes and text mining of records from OMIM and PubMed was used to generate phenotype vectors 
Table 5 Gene prioritisation of differentially expressed proteins between NOD vs C57Bl/6 islets: ten highest ranked proteins

\begin{tabular}{|c|c|c|c|c|c|c|c|c|}
\hline \multirow[t]{2}{*}{ Spot no. } & \multirow[t]{2}{*}{ Protein name } & \multirow[t]{2}{*}{ Protein symbol } & \multirow[t]{2}{*}{ UniProt acc. no. } & \multicolumn{2}{|c|}{ OMIM } & \multicolumn{2}{|c|}{ PubMed } & \multirow[b]{2}{*}{ Average rank } \\
\hline & & & & Rank & Top partner & Rank & Top partner & \\
\hline 686 & Protein disulfide-isomerase A3 & PDIA3 & P27773 & 4 & SUMO4 & 2 & SUMO4 & 3 \\
\hline $409 ; 411$ & Protein disulfide-isomerase A4 & PDIA4 & P08003 & 6 & HLA-DRA & 4 & HLA-DRA & 5 \\
\hline 2384 & Tropomyosin alpha-3 chain & TPM3 & P21107 & 2 & SUMO4 & 9 & SUMO4 & 5.5 \\
\hline 1440 & Thioredoxin-like protein 1 & TXNL1 & Q8CDN6 & 1 & SUMO4 & 14 & SUMO4 & 7.5 \\
\hline $1680 ; 1737$ & Endoplasmic reticulum resident protein 29 & ERP29 & P57759 & 12 & HLA-B & 3 & HLA-B & 7.5 \\
\hline 1814 & High mobility group protein B1 & HMGB1 & P63158 & 3 & HNF1A & 12 & HNF1A & 7.5 \\
\hline 1740 & Latexin & LXN & P70202 & 8 & SPINK1 & 13 & SLIT3 & 10.5 \\
\hline 1723 & 14-3-3 protein epsilon & $1433 \mathrm{E}$ & P62259 & 17 & HNF1A & 5 & HLA-DRB1 & 11 \\
\hline 810 & Dipeptidyl peptidase 2 & DPP2 & Q9ET22 & 5 & SIAE & 19 & CD109 & 12 \\
\hline $289 ; 294$ & Ezrin & EZRI & P26040 & 14 & HLA-B & 11 & HLA-B & 12.5 \\
\hline
\end{tabular}

Human orthologues of mouse genes were assigned to type 1 diabetes relevant protein complexes and text mining of records from OMIM and PubMed was used to generate phenotype vectors

NEC2, AKP0, EZRI, KAD1, PDIA6) were also highly ranked by gene prioritisation, indicating the importance of these genes in relation to type 1 diabetes.

In line with the reported limited correlation between mRNA and protein levels [28], our results show only a minor overlap between differentially expressed transcripts and proteins. However, when performing more integrated pathway and network analyses on the microarray and proteomics data, the overall groups of biological processes enriched in the differentially expressed genes and proteins in NOD islets were remarkably similar for both comparisons. A major role was premised for proteins related to metabolic and cellular processes. Primary metabolic processes are essential for the normal anabolic and catabolic pathways such as carbohydrate, lipid and protein metabolism. A defect in genes responsible for the supply of carbohydrates, needed for optimal energy production in islets, could be one of the predisposing factors for diabetes development in NOD mice. It has indeed been described that changes in metabolic demands precede type 1 diabetes, both in humans and NOD mice [29]. Concerning the group related to cellular processes, mainly genes/proteins involved in cell communication, genes functioning as cell surface receptors for cytokines and growth factors, protein kinases and proteins involved in the secretion machinery were altered in NOD islets.

Enrichment analysis of the differential genes in NOD vs $\mathrm{C} 57 \mathrm{Bl} / 6$ islets revealed dysregulation of genes related to metal ion transport, in line with recent studies showing that pancreatic changes in $\mathrm{Zn}^{2+}$ levels influence the availability and action of insulin [30, 31]. In addition, genes implicated in the regulation of protein kinase activity were affected in NOD islets, which could lead to disturbances in the regulation of several molecular processes. As such, cGMP-specific 3',5'-cyclic phosphodiesterase (PDE5A), catalysing the hydrolysis of cGMP to 5'-GMP, was found to be lower expressed in NOD islets. Since it was shown that inhibition of this enzyme potentiates beta cell death, a similar effect is expected in NOD islets [32]. Furthermore, lower expression of the Wnt signalling pathway modulator Sfrp5, as observed in NOD islets in the present study, has been described to improve insulin sensitivity but impair beta cell function [33].

Based on the IPA pathway analysis, we retrieved Hnfla as an upstream regulator of several differentially expressed genes, which was confirmed by qRT-PCR. Mutations in this gene are known to cause MODY and large-scale genetic studies have shown an association of genetic variants with type 2 diabetes [34]. The relationship with these phenotypes implicates an important role for Hnfla in beta cells. Coherently, experimental studies showed that this transcription factor controls beta cell function and growth by regulating the gene expression of glucose transporter 2, pyruvate kinase, collectrin, hepatocyte growth factor activator and Hnf4a [34].

PDIA3, 4 and 6 are indicated as proteins that play a crucial role in NOD islets, since they were highly ranked by gene prioritisation and were central in PPI networks. The function of these enzymes, which have lower expression in NOD islets compared with both control mice strains, is to rearrange S-S bonds, making them crucial for correct protein folding. An important role for PDIAs in beta cell functioning has already been described, especially for PDIA6. Together with other chaperones such as GRP78 and calreticulin, PDIA6 is responsible for the correct folding of proinsulin, and silencing of PDIA6 in mouse beta cells reduces insulin production $[35,36]$. Furthermore, compared with native proinsulin, binding of PDIA6 is ten times higher to misfolded proinsulin containing the Akita mutation, 
Table $6 I d d$ loci localisation of differentially expressed genes in NOD vs NOR and NOD vs C57B1/6 islets

\begin{tabular}{|c|c|c|}
\hline $\begin{array}{l}\text { Idd } \\
\text { locus }\end{array}$ & NOD vs NOR & NOD vs $\mathrm{C} 57 \mathrm{Bl} / 6$ \\
\hline Idd 1 & Rnf5 & $C 2, H 2-A a, H 2-A b 1, H 2-E b 1, H 2-K 1, H 2-K e 6, P s m b 8$ \\
\hline$I d d 2$ & AF529169, Cbl, Hercl & $\begin{array}{l}\text { Alg9, Bco2, C2cd4b, Elmod1, Fam81a, Filip1, Fxyd6, Fxyd6, Gramd1b, Gsta4, } \\
\text { Hmgcll1, Hspa8, Htr3a, Irak1bp1, Kif23, Lrrc1, Ncam1, Oaf, Rcn2, Sema7a, } \\
\text { Snord14e, Sorl1, Spsb4, Tmprss4, Zwilch }\end{array}$ \\
\hline$I d d 3$ & 4932438A13Rik & Cetn4 \\
\hline Idd4 & $\begin{array}{l}\text { 6330403K07Rik, Acsl6, Atox 1, Bcl6b, Glra1, Lyrm7, } \\
\text { Mink1, Mis12, Pdlim4, Psmb6, Sec24a, Snord95 }\end{array}$ & Acsl6, Btnl9, Glra1, Lyrm 7, P4ha2, Pdlim4, Sgcd \\
\hline Idd5 & Cdh7, Dock10, Nfasc, R3hdm1, Smg7 & $\begin{array}{l}\text { Acadl, Arpc5, Atp2b4, Cdh19, Dner, Dock10, Fam163a, Gm7582, Hjurp, Kcnj13, } \\
\text { Nhej1, Npl, Pigr, Qsox1, Scg2, Serpine2, Vill, Wdfy1 }\end{array}$ \\
\hline Idd6 & Slcolab & Itpr2, Kras, Pde3a, Pik3c2g, Rassf8, Recql, Slcola5, Slcola6 \\
\hline Idd 8 & / & Plau \\
\hline$I d d 9$ & Angptl7, Rbp7 & Angptl7, Eno1, Gpr157, Rbp7 \\
\hline Idd11 & Laptm5, Pef1, Phactr4, Psmb2, Sytl1, Txlna & Cd164l2, Sytl1, \\
\hline $\operatorname{Idd} 13$ & $\begin{array}{l}\text { Cdk5rap1, Chchd5, Commd7, Ino80, Lbp, Ncoa6, Nfs 1, } \\
\quad \text { Slc28a2, Spg11 }\end{array}$ & $\begin{array}{l}\text { Acss2, Bub1, Bub1b, Cd93, Commd7, Frmd5, Gm14085, Ivd, Lbp, Macrod2, } \\
\quad \text { Ndufaf1, Nfs1, Pigu, Polr1b, Slc28a2, Tpx2 }\end{array}$ \\
\hline $\operatorname{Idd} 14$ & 2210016F16Rik, Hivep1, Nsd1, Phactr1, Rasgrf2, & $\begin{array}{l}\text { 4833439L19Rik, Cap2, Cast, Erap1, Fbp2, Gcnt2, Gm10260, Gm6404, Gmpr, } \\
\text { Golm1, Hapln1, Marveld2, Mccc2, Nnt, Phactr1, Ppap2a, Rgs7bp, Slc22a23, } \\
\text { Spock1, Tert, Zfp87, }\end{array}$ \\
\hline $\operatorname{Idd} 16$ & / & Clps, Fkbp5, Itfg3, Neurl1b \\
\hline Idd 17 & / & Glrb, Gucyla3 \\
\hline $\operatorname{Idd} 19$ & Wnk1, Zfp637 & Cdca3, Eno2, Mical3, Ncapd2, Rimklb, \\
\hline $\operatorname{Idd} 20$ & Nup210, & Nup210, Pcyox1, Snrnp27 \\
\hline $\operatorname{Idd} 21$ & Cbln2, Mib1, Riok3 & Cbln2, Ccdc68, Ttr, Zadh2 \\
\hline $\operatorname{Idd} 23$ & Abca3, Eci1, Nme3, Tulp4 & Msln, Mslnl, Pacrg, Rps2, Wtap \\
\hline $\operatorname{Idd} 24$ & Znrd1 & $H 2-T 22, H 2-T 23, H 2-T 24$ \\
\hline $\operatorname{Idd} 26$ & Tmem131 & Ptp4a1 \\
\hline $\operatorname{Idd} 27$ & Acsm3, Mical2, Pgap2, Syt9, Tmc7, Trim12a, Wee1 & $\begin{array}{l}\text { Fah, Hddc3, Iqgap1, Kcne3, Lyve1, Olfr558, Pde2a, Pgap2, Plekhb1, Prc1, Prcp, } \\
\text { Relt, Rrp8, Syt9, Trim12a, Trim12c, Wee1 }\end{array}$ \\
\hline
\end{tabular}

Genes that are differentially expressed in both NOD vs NOR and NOD vs C57Bl/6 are indicated in bold

T1DBase was used to categorise the genes [44]

where it plays a key role in targeting this misfolded protein to the ER degradation pathway [35]. Based on this knowledge, it is conceivable that lower expression of PDIA6 in NOD islets leads to higher levels of unfolded proteins, activation of the unfolded protein response and consequently induction of ER stress. It is well known that beta cell death is associated with increased levels of oxidative, ER and mitochondrial stress, and that stress response genes, such as Chop, Jnk, Xbpls and Puma, are induced in cytokine-treated beta cells, as well as in isolated islets from prediabetic and diabetic NOD mice [37-39]. However, in our study, the expression of these genes was not increased in islets from 2-3-week-old NOD mice. This suggests that intrinsic defects in proper
Table 7 Idd loci localisation of differentially expressed proteins in NOD vs NOR and NOD vs $\mathrm{C} 57 \mathrm{Bl} / 6$ islets

\begin{tabular}{lll}
\hline Idd locus & NOD vs NOR & NOD vs C57B1/6 \\
\hline$I d d 2$ & ODP2 & DCPS (2), HSP7C, SCG3 (2) \\
$I d d 13$ & GSHB, NEC2, NSF1C, PDIA3 & NEC2 (4), PDIA3, SAHH \\
$I d d 14$ & $/$ & HNRPK (2) \\
$I d d 19$ & $/$ & ENOG \\
$I d d 23$ & EZRI & EZRI (2) \\
\hline
\end{tabular}

Proteins that are differentially expressed in both NOD vs NOR and NOD vs C57Bl/6 are indicated in bold When more than one spot was differentially expressed, the number is written in brackets

T1DBase was used to categorise the genes [44] 
protein folding, associated with the significantly lower expression of PDIAs in NOD islets vs NOR and C57Bl/ 6 , is one of the first triggers for enhanced stress in beta cells, thereby underlying the high susceptibility for beta cell dysfunction and death. These findings are also in line with a report by Yang et al who compared islets from 3-week-old NOD mice with $A L R / L t$ mice by $2 \mathrm{D}$ gel analysis, demonstrating lower expression of PDIAs and several heat shock proteins [27]. In addition, PDIAs are also involved in regulation of cytoskeleton organisation, especially by modification of beta-actin [40]. As such, lower expression of PDIAs in NOD islets may be central to a significant amount of differential genes/proteins linked to cytoskeleton and cell communication.

One of the cytoskeleton proteins that shows an altered expression in NOD compared with C57Bl/6 and NOR islets is EZR, which is expressed together with other proteins from the ERM scaffolding protein family in beta cells, namely radixin and moesin. These ERM proteins are activated by phosphorylation, induced by glucose and calcium, leading to cell surface translocation, where they participate in traffic and release of insulin granules [41]. However, in contrast to the high expression observed in NOD islets, islets of diabetic $o b /$ $o b$ mice, a model for type 2 diabetes, are characterised by less active ERM [41]. Despite this, perturbations in the cytoskeleton of beta cells can have crucial implications for proper insulin secretion, and disturbed interaction between beta cells and the environment may lead to impaired beta cell functioning in general.

Of interest, a number of the differentially expressed genes and proteins in NOD islets have already been associated with type 1 diabetes since they map to specific Idd loci (Tables 6, 7), such as PDIA3 and EZR described above. Also the majority of the most differential genes in NOD islets (Table 1), confirmed by qRT-PCR, map to these loci (Table 6).

Finally, the most remarkable finding in NOD islets at this early preinsulitic age was the high expression of Padi2 mRNA, confirming our earlier findings by qRT-PCR [42]. This suggests that Padi2 is the diabetes susceptibility gene located in Idd25, a region on $\mathrm{Chr} 4$ for which the importance in diabetes development was already suggested by the generation of subcongenic strains between NOD and NOR mice. In favour of this hypothesis, no regulation was observed for Ephb2, the gene closely located to Padi2 in the Idd25 locus [43]. As we suspect only very low or no immune cells in the islets at the investigated age, the expression of Padi2 in endocrine cells was supported by similar expression levels in NOD.scid islets, further emphasising the importance of citrullination in NOD mice [39]. Previous results from our group showed that the ER chaperone GRP78 is citrullinated in beta cells upon inflammatory stress and that citrullinated GRP78 is an auto-antigen in NOD mice. Results from the 2D-DIGE analysis in the present study further highlight the presence of several proteins which are PTM modified in NOD islets, a finding that has not been reported by an earlier proteomic study on NOD islets [27]. The presence of different modified isoforms may point to a role for citrullination, not only for GRP78 but also for other islet proteins.

In conclusion, we have shown that islets of preinsulitic NOD mice already have a significantly differential mRNA and protein expression profile compared with control NOR and C57B1/6 islets. An important role for PDIAs was suggested in NOD islets, where low expression of these chaperones required for S-S bond formation and crucial for correct insulin folding can lead to accumulation of unfolded proteins, activation of the unfolded protein response and generation of ER stress in beta cells. Additionally, high expression of Padi2 mRNA, coding for the enzyme responsible for citrullination, together with the presence of several proteins in multiple isoforms, indicates that PTMs in beta cells are of high importance for type 1 diabetes susceptibility. Modifications can affect protein function but also create neo-epitopes that can be recognised as auto-antigens. In general, the findings from the present study point towards a crucial role of the beta cell itself, independent of differences present at the level of the immune system, in the susceptibility and initiation of type 1 diabetes.

Acknowledgements The technical experience of J. Laureys, M. Gilis, E. Verdrengh, W. Werckx, F. Coun (Laboratory for Clinical and Experimental Endocrinology, KU Leuven, Leuven, Belgium) and S. Vandoninck (Laboratory of Protein Phosphorylation and Proteomics, KU Leuven, Leuven, Belgium) is greatly appreciated.

Data availability All microarray data are available in the ArrayExpress database (www.ebi.ac.uk/arrayexpress) under accession number EMTAB-5264.

Funding This work was supported by the KU Leuven (Geconcerteerde Onderzoeksactie GOA 12/24), the Flemish Research Foundation (FWO 1508515 N, G.0619.12 and a clinical research fellowship for CM) and a $\mathrm{PhD}$ fellowship from IWT for IC.

Duality of interest The authors declare that there is no duality of interest associated with this manuscript.

Author contribution IC, WDH, CG, $\mathrm{LO}$ and $\mathrm{CM}$ contributed to the conception and design, analysis and interpretation of data, drafting or revising the article. VG and SB analysed protein-protein interactions, made networks, performed gene prioritisation and interpreted these data. LVL, FS, ACF and KM designed, performed and analysed the microarray experiments. EW was responsible for MS/MS proteome analysis. SV and FMCS contributed to the design, analysis, interpretation and drafting of the additional experiments during revision. All authors revised the article and gave their final approval of the version to be published. $\mathrm{CM}$ is the guarantor of this work. 


\section{References}

1. Anderson MS, Bluestone JA (2005) The NOD mouse: a model of immune dysregulation. Annu Rev Immunol 23:447-485

2. Thomas HE, Kay TW (2000) Beta cell destruction in the development of autoimmune diabetes in the non-obese diabetic (NOD) mouse. Diabetes Metab Res Rev 16:251-261

3. Todd JA, Bell JI, McDevitt HO (1987) HLA-DQ beta gene contributes to susceptibility and resistance to insulin-dependent diabetes mellitus. Nature 329:599-604

4. Wicker LS, Todd JA, Peterson LB (1995) Genetic control of autoimmune diabetes in the NOD mouse. Annu Rev Immunol 13:179200

5. Driver JP, Serreze DV, Chen Y-G (2011) Mouse models for the study of autoimmune type 1 diabetes: a NOD to similarities and differences to human disease. Semin Immunopathol 33:67-87

6. Barrett JC, Clayton DG, Concannon P et al (2009) Genome-wide association study and meta-analysis find that over 40 loci affect risk of type 1 diabetes. Nat Genet 41:703-707

7. Serreze DV, Prochazka M, Reifsnyder PC et al (1994) Use of recombinant congenic and congenic strains of NOD mice to identify a new insulin-dependent diabetes resistance gene. J Exp Med 180: $1553-1558$

8. Carrero JA, Calderon B, Towfic F et al (2013) Defining the transcriptional and cellular landscape of type 1 diabetes in the NOD mouse. PLoS One 8, e59701

9. Aspord C, Rome S, Thivolet C (2004) Early events in islets and pancreatic lymph nodes in autoimmune diabetes. J Autoimmun 23: $27-35$

10. Kakoola DN, Curcio-Brint A, Lenchik NI, Gerling IC (2014) Molecular pathway alterations in CD4 T cells of nonobese diabetic (NOD) mice in the preinsulitis phase of autoimmune diabetes. Res Immunol 4:30-45

11. Kodama K, Butte AJ, Creusot RJ et al (2008) Tissue- and agespecific changes in gene expression during disease induction and progression in NOD mice. Clin Immunol 129:195-201

12. Wu J, Kakoola DN, Lenchik NI et al (2012) Molecular phenotyping of immune cells from young NOD mice reveals abnormal metabolic pathways in the early induction phase of autoimmune diabetes. PLoS One 7, e46941

13. McGinty JW, Marré ML, Bajzik V et al (2015) T cell epitopes and post-translationally modified epitopes in type 1 diabetes. Curr Diab Rep 15:90

14. Marré ML, James EA, Piganelli JD (2015) $\beta$ cell ER stress and the implications for immunogenicity in type 1 diabetes. Front Cell Dev Biol 3:67

15. Doyle HA, Mamula MJ (2012) Autoantigenesis: the evolution of protein modifications in autoimmune disease. Curr Opin Immunol 24:112-118

16. Doyle HA, Yang M-L, Raycroft MT et al (2014) Autoantigens: novel forms and presentation to the immune system. Autoimmunity 47:220-233

17. Zavala-Cerna MG, Martínez-García EA, Torres-Bugarín O et al (2014) The clinical significance of posttranslational modification of autoantigens. Clin Rev Allergy Immunol 47:73-90

18. Gysemans CA, Waer M, Valckx D et al (2000) Early graft failure of xenogeneic islets in NOD mice is accompanied by high levels of interleukin-1 and low levels of transforming growth factor-beta mRNA in the grafts. Diabetes 49:1992-1997

19. Gysemans C, Callewaert H, Overbergh L, Mathieu C (2008) Cytokine signalling in the beta-cell: a dual role for IFNgamma. Biochem Soc Trans 36:328-333

20. D'Hertog W, Overbergh L, Lage K et al (2007) Proteomics analysis of cytokine-induced dysfunction and death in insulin-producing
INS-1E cells new insights into the pathways involved. Mol Cell Proteomics 6:2180-2199

21. Lage K, Karlberg EO, Størling ZM et al (2007) A human phenomeinteractome network of protein complexes implicated in genetic disorders. Nat Biotechnol 25:309-316

22. Smoot ME, Ono K, Ruscheinski J, Wang PL, Ideker T (2011) Cytoscape 2.8: new features for data integration and network visualization. Bioinformatics 27:431-432

23. Jiang L, Sørensen P, Thomsen B et al (2012) Gene prioritization for livestock diseases by data integration. Physiol Genomics 44:305317

24. Mi H, Muruganujan A, Thomas PD (2013) PANTHER in 2013: modeling the evolution of gene function, and other gene attributes, in the context of phylogenetic trees. Nucleic Acids Res 41:D377D386

25. Carbon S, Ireland A, Mungall CJ et al (2009) AmiGO: online access to ontology and annotation data. Bioinformatics 25:288-289

26. Gerling IC, Singh S, Lenchik NI et al (2006) New data analysis and mining approaches identify unique proteome and transcriptome markers of susceptibility to autoimmune diabetes. Mol Cell Proteomics 5:293-305

27. Yang P, Li M, Guo D et al (2008) Comparative analysis of the islet proteome between NOD/Lt and ALR/Lt mice. Ann N Y Acad Sci 1150:68-71

28. Hack CJ (2004) Integrated transcriptome and proteome data: the challenges ahead. Brief Funct Genomic Proteomic 3:212-219

29. Sysi-Aho M, Ermolov A, Gopalacharyulu PV et al (2011) Metabolic regulation in progression to autoimmune diabetes. PLoS Comput Biol 7, e1002257

30. Rutter GA, Chabosseau P, Bellomo EA et al (2016) Intracellular zinc in insulin secretion and action: a determinant of diabetes risk? Proc Nutr Soc 75:61-72

31. Slepchenko KG, Daniels NA, Guo A, Li YV (2015) Autocrine effect of $\mathrm{Zn}^{2+}$ on the glucose-stimulated insulin secretion. Endocrine 50:110-122

32. Russell MA, Morgan NG (2010) Expression and functional roles of guanylate cyclase isoforms in BRIN-BD11 $\beta$-cells. Islets 2:374 382

33. Carstensen-Kirberg M, Hatziagelaki E, Tsiavou A et al (2016) Sfrp5 associates with beta-cell function in humans. Eur J Clin Invest 46:535-543

34. Yamagata $\mathrm{K}$ (2014) Roles of $\mathrm{HNF} 1 \alpha$ and $\mathrm{HNF} 4 \alpha$ in pancreatic $\beta$ cells: lessons from a monogenic form of diabetes (MODY). Vitam Horm 95:407-423

35. Gorasia DG, Dudek NL, Safavi-Hemami H et al (2016) A prominent role of PDIA6 in processing of misfolded proinsulin. Biochim Biophys Acta 1864:715-723

36. Eletto D, Eletto D, Boyle S, Argon Y (2016) PDIA6 regulates insulin secretion by selectively inhibiting the RIDD activity of IRE1. FASEB J 30:653-665

37. Tersey SA, Nishiki Y, Templin AT et al (2012) Islet $\beta$-cell endoplasmic reticulum stress precedes the onset of type 1 diabetes in the nonobese diabetic mouse model. Diabetes 61:818-827

38. Chan JY, Luzuriaga J, Maxwell EL et al (2015) The balance between adaptive and apoptotic unfolded protein responses regulates $\beta$-cell death under ER stress conditions through XBP1, CHOP and JNK. Mol Cell Endocrinol 413:189-201

39. Gorasia DG, Dudek NL, Veith PD et al (2015) Pancreatic beta cells are highly susceptible to oxidative and ER stresses during the development of diabetes. J Proteome Res 14:688-699

40. Sobierajska K, Skurzynski S, Stasiak M et al (2014) Protein disulfide isomerase directly interacts with $\beta$-actin Cys 374 and regulates cytoskeleton reorganization. J Biol Chem 289:5758-5773

41. Lopez JP, Turner JR, Philipson LH (2010) Glucose-induced ERM protein activation and translocation regulates insulin secretion. Am J Physiol Endocrinol Metab 299:E772-E785 
42. Rondas D, Crèvecoeur I, D’Hertog W et al (2015) Citrullinated glucose-regulated protein 78 is an autoantigen in type 1 diabetes. Diabetes 64:573-586

43. Stolp J, Chen Y-G, Cox SL et al (2012) Subcongenic analyses reveal complex interactions between distal chromosome 4 genes controlling diabetogenic B cells and CD4 T cells in nonobese diabetic mice. J Immunol 189:1406-1417

44. Burren OS, Adlem EC, Achuthan P et al (2011) T1DBase: update 2011, organization and presentation of large-scale data sets for type 1 diabetes research. Nucleic Acids Res 39:D997-D1001 